\title{
Assessing the organisational climate for creativity in a UK Public Library Service: a case study
}

\author{
Béatrice Coveney
}

\begin{abstract}
The study aims to investigate for the first time library staff's individual perceptions of their work environment with regard to creativity. It uses the conceptual model designed by Amabile et al. (1996) as a framework in order to establish to what extent the internal climate factors that are conducive or deterrent to creativity are identified by library staff in one UK Public Library service. This research is based on a case study and can constitute a benchmark for other library services. The ability to develop a culture that nurtures creativity is crucial and does not occur spontaneously: library managers need to take responsibility to establish the right work environment as well as to incorporate an innovation strategy for the new ideas to be implemented into value-added services for the library users.
\end{abstract}

\section{Introduction}

Choosing a topic for a dissertation is not always an easy task for any student, however distance learners often have a slight advantage as they can integrate their work experience into their studies. Creativity became an obvious topic for me as I cannot imagine a day at work without it: an intrinsic motivation, like humour can be at times! Publishing my findings in this article is also part of the creative process and I hope some of the ideas developed here will generate further thoughts and investigations from our information profession.

In order to collect data for my dissertation, I interviewed a number of senior librarians and one of them was very keen to recruit creative people because, according to her, they are able to invent ways to turn a boring job into an interesting one or to do things around it to make their work exciting. It is because creative people are able to maintain their own enthusiasm that they are able to inspire others. Last November, I attended a workshop on creativity with the photographer Chris Chapman who explained how he worked. What struck me

\section{Béatrice Coveney}

Béatrice Coveney works for Devon Libraries and is Chair of the Career Development Group Devon \& Cornwall Division.

E-mail: beatrice.coveney@devon.gov.uk 
was his great sensitivity to the outside world and his aptitude to perceive things that others cannot see. His photographs were a means to transcribe the emotion felt at the time: a kind of magnifying glass for the rest of us. I came to the conclusion that inspiration does not appear by magic, but finds its source from the outside environment, and if library managers are serious about developing creativity in their library service, it becomes apparent that they need to establish a stimulating work environment for library staff to release their potential creativity.

Before we investigate a reliable tool to assess a library work environment for creativity and the methodology used, it seems necessary to define what we mean by creativity and why it has become a crucial skill to possess in the library profession.

\section{What is creativity?}

The terms "creativity" and "innovation" are often phrased together as they are very much linked. Although there are some variations in meaning, it has been suggested that creativity is the generation of ideas and innovation is the implementation of these ideas (Ensor et al., 2001 and Heye, 2006). Harvard Business School sees innovation as a process and that process begins with two creative acts: idea generation and opportunity recognition. They recognise that in most cases, a problem or an opportunity inspires the insight. The following chart summarises the innovation process:

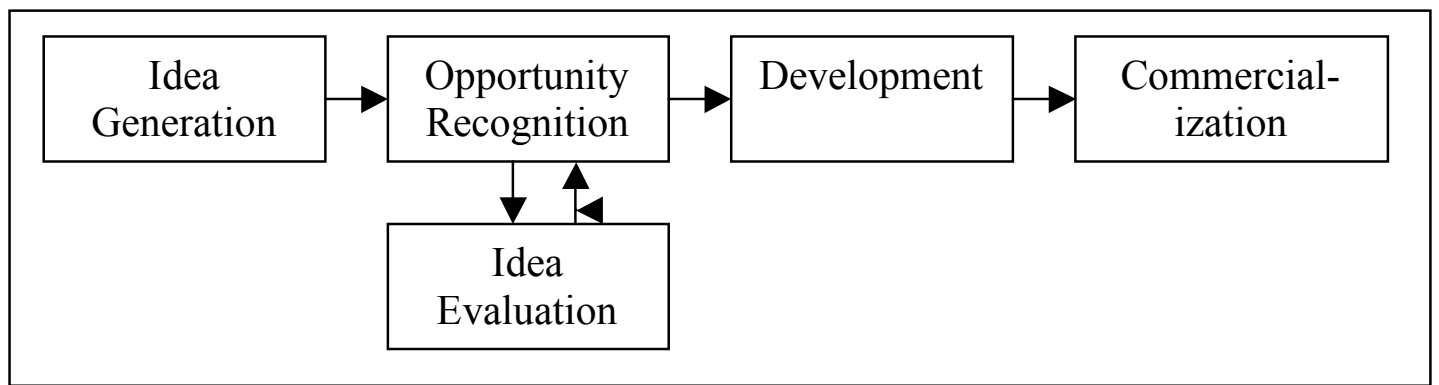

Figure 1: The innovation process

(Source: HMM Managing for Creativity and Innovation, 2003)

A distinction is also made between incremental and radical innovation. The former either improves upon something that already exists or an existing form is adapted to serve some other purpose. By contrast, radical innovation is something totally new to the world and can take the form of a new product, process or service. The risk involved in implementing radical innovation is much higher than with incremental ones, however the rewards can be as high as the risk taken (HMM, 2003). Borghini (2005) considers that the most common features attributed to creativity are the concepts of novelty/originality and usefulness/value, which appear in different definitions of creativity (Amabile, 1996; Mayer, 1999). Finally, creativity and innovation are often associated to change (Drucker, 1985), and it must be emphasized that the implementation of a new idea leads to change, however change cannot always be regarded as innovative as it does not necessary involve new ideas (Farr and West, 1990). In other words, some library services can be very successful in implementing 
change; it does not necessarily imply that they show great originality. And so what? Is it not better to keep a safe approach and try something that has been tested previously by others? Adopting such an attitude may reinforce the idea that Public libraries are part of an old established institution but certainly not a dynamic and inspiring place for the younger generation to be, which may not be helpful in securing their future.

\section{Why is creativity important?}

Looking at the vast amount of research dedicated to organisational creativity, one cannot help wondering what the fuss is all about. A recent survey carried out in the USA has revealed that creativity was ranked in the top five by corporate leaders as the most critical skill that employees needed to demonstrate (HR Focus, 2007). According to Marshall Egan, the fostering of creativity

is a necessity, not an option, for most organizations interested in responding to: (a) advancing technology; (b) a changing environment; (c) changing organizational structures or strategies; (d) overcoming competitors that improve their products, processes, and services; (e) evolving customer desires; and (f) evolving societies influenced increasingly by global issues and diversity.

(Marshall Egan, 2005, 161)

Public Library services have by no means been spared in this turbulent world, having had to deal with changing users' behaviours, financial constraints, rapidly evolving technologies and the impact of government policy (Walton, 2008) and their success and survival depend on creativity if library managers want to ensure their existence in the years to come. One may still consider that responding appropriately to the changing environment is a lesser concern for a public sector than for private businesses. Light (1998) described the critical difference between innovation in the private sector and innovation in the public sector:

Whereas in the private sector an innovation merely needs to be profitable to be worth doing, in the public sector innovation must be about doing something worthwhile... Second, public sector innovation involves more than simply doing the public's business well... Third, non-profit and government innovation involves the broader public good. The ultimate purpose of innovation is not to win awards, boost public confidence, or attract foundation support, but to create public value.

(Light, 1998: xv)

\section{Recent research on creativity}

Creativity has also addressed using a range of perspectives and at least three different levels of analysis: intrasubjective (focusing on the individual), intersubjective (individuals interacting with each other) and collective (the cultural environment that influences the employees' creativity: Anderson and West, 1998; West, 2001). A growing number of papers suggest that the complexity in the relationships among variables involved in the organisational creative process requires a multi-dimensional approach (Rousseau, 1985; 
Woodman et al., 1993; House et al., 1995; Chan, 1998; Drazin et al., 1999; Williams and Yang, 1999; Borghini, 2005).

Borghini (2005) offers a valuable conceptual approach to organisational creativity, where creativity brings variety to the organisation that integrates it into organisational knowledge that reinforces creativity. The limit to the growth in the creative process is the so-called "core rigidities" or the inability to abandon rules and consolidated knowledge which have proven to be effective in the past. Although this piece of research brings an invaluable insight in the dynamics that brings about or prevents creativity, it does not evaluate a desirable degree for these two dynamics to coexist together so organisational creativity is still happening despite the obstacles.

Comparatively little has been written in the information profession, in particular regarding guidance in fostering creativity at work. However, three recent papers focusing on creativity and innovation in the context of libraries provided useful insights: Heye (2006) offers some valuable practical creativity and innovation tips, while Deiss (2004) reviews recent theories of innovation and strategy in a non-profit organisational environment, particularly libraries. She stresses that strategy can exist without innovation, but the effective implementation of innovation is unlikely to happen without the use of strategy. This view is further developed by Walton (2008), who stresses the relevance of creativity in the strategic management of libraries as well as the importance for the library manager to take responsibility for creativity to occur and develop within the library service. Deiss (2004) also describes libraries as mature organisations with a culture that is more likely to develop "core rigidities" (Borghini, 2004) and she believes that "developing a baseline for the organisation is an important first step in assessing areas for development" (Deiss, 2004, 27), but also stresses that she is unaware of any work carried out assessing organisational creativity in libraries.

\section{Assessing the work environment for creativity}

Mathiesen and Einarsen (2004) reviewed the available instruments for measuring aspects of the work environment conducive to creativity and innovation. Five instruments were assessed: KEYS: Assessing the Climate for Creativity; Creative Climate Questionnaire; Situational Outlook Questionnaire; Team Climate Inventory; and Siegel Scale of Support for innovation. Only two instruments (KEYS: Assessing the Climate for Creativity and Team Climate Inventory) were considered by Mathiesen and Einarsen (2004) to be of acceptable scientific quality and were well documented in literature. The difference between the two instruments is that the KEYS approach sees climate as individual perceptions of environmental factors on different levels: organisational, supervisory, group and individual, whereas the Team Climate Inventory's approach views climate as shared perceptions and assesses team climate. Mathiesen and Einarsen (2004) conclude that the key finding from these studies is that work environment quality does have an impact on the level of creativity and innovation in group and organisations.

Ensor et al. $(2001,2006)$ produced some interesting studies on the work environment for creativity in the UK advertising industry using the KEYS tool's 
dimension model: the first study consists of 30 in-depth interviews whereas the latter makes use of the KEYS instrument tool and aims to identify whether the work environment of advertising agencies display the key elements of the conceptual categories that Amabile et al. hypothesise influence organisational creativity. On the whole, Ensor et al. 's (2006) findings support Amabile et al.'s conceptual framework, however further refinements of the KEYS instrument are suggested especially on the challenging work and workload pressure scales, which seems to reinforce Mathiesen and Einarsen (2004)'s findings concerning the need to further improve the KEYS instrument.

Although creativity is a desirable skill to nurture, there are some people who advocate a more balanced view on managing innovation and change. In The Ambidextrous Organisation, Birkinshaw and Gibson (2005) advocate the achievement by organisations of the right balance between adaptability (the ability to plan for the future) and alignment (the ability to deal with present). They use the example of Ericsson which was hit hard during a crash in the telecom industry and was forced to concentrate on the present and to close many of its technology centres. This shows the negative impact when this balance is not achieved. They also stress the need to assess their organisational context and offer a simple tool to use but it gives a quick indication of some quantitative measurement.

\section{Methodology}

The focus of my study was to assess the perceptions of public library staff of their work environment fostering creativity, more precisely it aimed to identify the values, norms and beliefs of the staff working at different levels within a public library service and forming an organisational culture. Bath and North East Somerset (BANES) Library and Information Service kindly gave permission for me to conduct this study by approaching volunteers among their staff in order to collect data for the research. Overall the service employs 9.3 FTE professional staff and 53.6 FTE other staff, equating to a staff count of 116.

As noted earlier, various approaches have been used in the past to assess the work environment for creativity, which solely use quantitative data or qualitative data or a combination of both in the form of questionnaires and interviews.

Two types of non-probability sampling were felt to be the most appropriate fieldwork methods as they take into account the relatively small survey population within BANES Library and Information Service and the voluntary nature of this research: convenience sampling to collect quantitative data and snowball sampling for qualitative data.

\subsection{Survey Strategy}

In order to gain a precise and comprehensive picture of the staff's perceptions of their work environment, a combination of survey techniques was decided on, in particular online self-completion questionnaire and in-depth interview. The aim of using online self-completion questionnaires is to ensure that the collected data can be aggregated and compared between variables as respondents are given identical cues, whereas the in-depth interview technique enables one to collect additional background information complementary to the questionnaire. 
The questionnaire is a simplified adaptation of the KEYS instrument: Assessing the Climate for Creativity.

\subsubsection{The Keys Instrument: Assessing the Work Environment for Creativity}

As noted earlier, Amabile's KEYS: Assessing the Climate for Creativity seems to offer an effective assessment tool on which to base the design of the present questionnaire. Although its factor structure has been questioned when tested by external researchers (Mathiesen and Einarsen, 2004; Ensor et al., 2006), since many statements referred to more than one factor, it nevertheless offers a solid starting point for assessing for the first time individual staff perceptions of a public library-based environment conducive to creativity. It also enables one to establish some comparisons with other similar studies (Amabile et al., 1996; Ensor et al, 2001, 2006) whose findings derived from use of this assessment tool and constitute a database of results and a set of norms which can be used as a baseline against the results obtained from this survey.

\subsubsection{Conceptual Model}

Amabile et al., in their conceptual model propose five conceptual categories (encouragement of creativity, autonomy or freedom, resources, pressures and organisational impediments to creativity). These are based on a review of previous research and on a critical incident study of 120 research and development scientists and technicians, who have been asked to describe high and low creativity events from their own work experience (Amabile et al., 1996).

\subsubsection{KEYS: the Instrument Tool}

The KEYS instrument developed from the conceptual model measures 5 categories using 10 scales reflecting various dimensions of the work environment. The survey consists of 78 items, in the form of positive or negative statements using a 4-point response scale: always or almost always, often, sometimes, and never or almost never. 


\begin{tabular}{|c|c|c|}
\hline Scale name & $\begin{array}{l}\text { Number of } \\
\text { items }\end{array}$ & Description \\
\hline \multicolumn{3}{|l|}{ Stimulant Scales } \\
\hline $\begin{array}{l}\text { Organizational } \\
\text { encouragement }\end{array}$ & 15 & $\begin{array}{l}\text { An organizational culture that encourages } \\
\text { creativity through the fair, constructive } \\
\text { judgement of ideas, reward and recognition } \\
\text { for creative work, mechanisms for developing } \\
\text { new ideas, an active flow of ideas, and a } \\
\text { shared vision of what the organization is } \\
\text { trying to do. }\end{array}$ \\
\hline $\begin{array}{l}\text { Supervisory } \\
\text { encouragement }\end{array}$ & 11 & $\begin{array}{l}\text { A supervisor, who serves as a good work } \\
\text { model, sets goals appropriately, supports the } \\
\text { work group, values individual contributions, } \\
\text { and shows confidence in the work group. }\end{array}$ \\
\hline $\begin{array}{l}\text { Work group } \\
\text { supports }\end{array}$ & 8 & $\begin{array}{l}\text { A diversity skilled work group in which } \\
\text { people communicate well, are open to new } \\
\text { ideas, constructively challenge each other's } \\
\text { work, trust and help each other and feel } \\
\text { committed to the work they are doing. }\end{array}$ \\
\hline Freedom & 4 & $\begin{array}{l}\text { Freedom in deciding what work to do or how } \\
\text { to do it; a sense of control over one's work. }\end{array}$ \\
\hline $\begin{array}{l}\text { Sufficient } \\
\text { resources }\end{array}$ & 6 & $\begin{array}{l}\text { Access to appropriate resources, including } \\
\text { funds, materials, facilities and information. }\end{array}$ \\
\hline Challenging work & 5 & $\begin{array}{l}\text { A sense of having to work hard on } \\
\text { challenging tasks and important projects. }\end{array}$ \\
\hline \multicolumn{3}{|l|}{ Obstacle scales } \\
\hline $\begin{array}{l}\text { Organizational } \\
\text { Impediments }\end{array}$ & 12 & $\begin{array}{l}\text { An organizational culture that impedes } \\
\text { creativity through internal political problems, } \\
\text { harsh criticism of new ideas, destructive } \\
\text { internal competition, an avoidance of risk, } \\
\text { and an overemphasis on the status quo. }\end{array}$ \\
\hline $\begin{array}{l}\text { Workload } \\
\text { Pressure }\end{array}$ & 5 & $\begin{array}{l}\text { Extreme time pressures, unrealistic } \\
\text { expectations for productivity, distractions } \\
\text { from creative work. }\end{array}$ \\
\hline \multicolumn{3}{|l|}{ Criterion scales } \\
\hline Creativity & 6 & $\begin{array}{l}\text { A creative organization or unit, where a great } \\
\text { deal of creativity is called for and where } \\
\text { people believe they actually produce creative } \\
\text { work. }\end{array}$ \\
\hline Productivity & 6 & $\begin{array}{l}\text { An efficient, effective and productive } \\
\text { organization or unit. }\end{array}$ \\
\hline
\end{tabular}

Figure 2: The KEYS environment scales

(Source: Amabile et al. (1996))

${ }^{1}$ The items refer to the 78 statements that constitute the KEYS questionnaire. 


\subsubsection{Design of the Online Self-Completion Questionnaire}

An online questionnaire seemed to be the most appropriate format to survey an entire organisation whose members of staff are scattered around a local authority. For the researcher, it also offers other advantages: not only does it preserve anonymity; it is an economic and effective way to reach potential participants via email and to receive their results immediately. The online format also enables one to mark all questions requiring an answer from the respondents before they can proceed to the next question, preventing the completion of questionnaires with missing data.

For the participating organisation, the online questionnaire is easy to use for the staff and reduces to a minimum the disruption of the staff's library work. Attention was also paid in the design phase to ensure that the amount of time required to complete the questionnaire should not exceed 10 minutes as the emphasis is on encouraging a maximum number of participants across the entire organisation. Therefore, the online questionnaire consists of only 24 positive or negative statements using the KEYS's 4-point response scale: always or almost always, often, sometimes, and never or almost never. The questionnaire is structured around four different levels: organisational, supervisory, group and individual and there are six statements for each level. The questionnaire aims to measure the five conceptual categories: encouragement of creativity, autonomy or freedom, resources, pressures, organisational impediments to creativity using eight scales.

\subsubsection{Breakdown of the items}

Data was collected in the following areas:

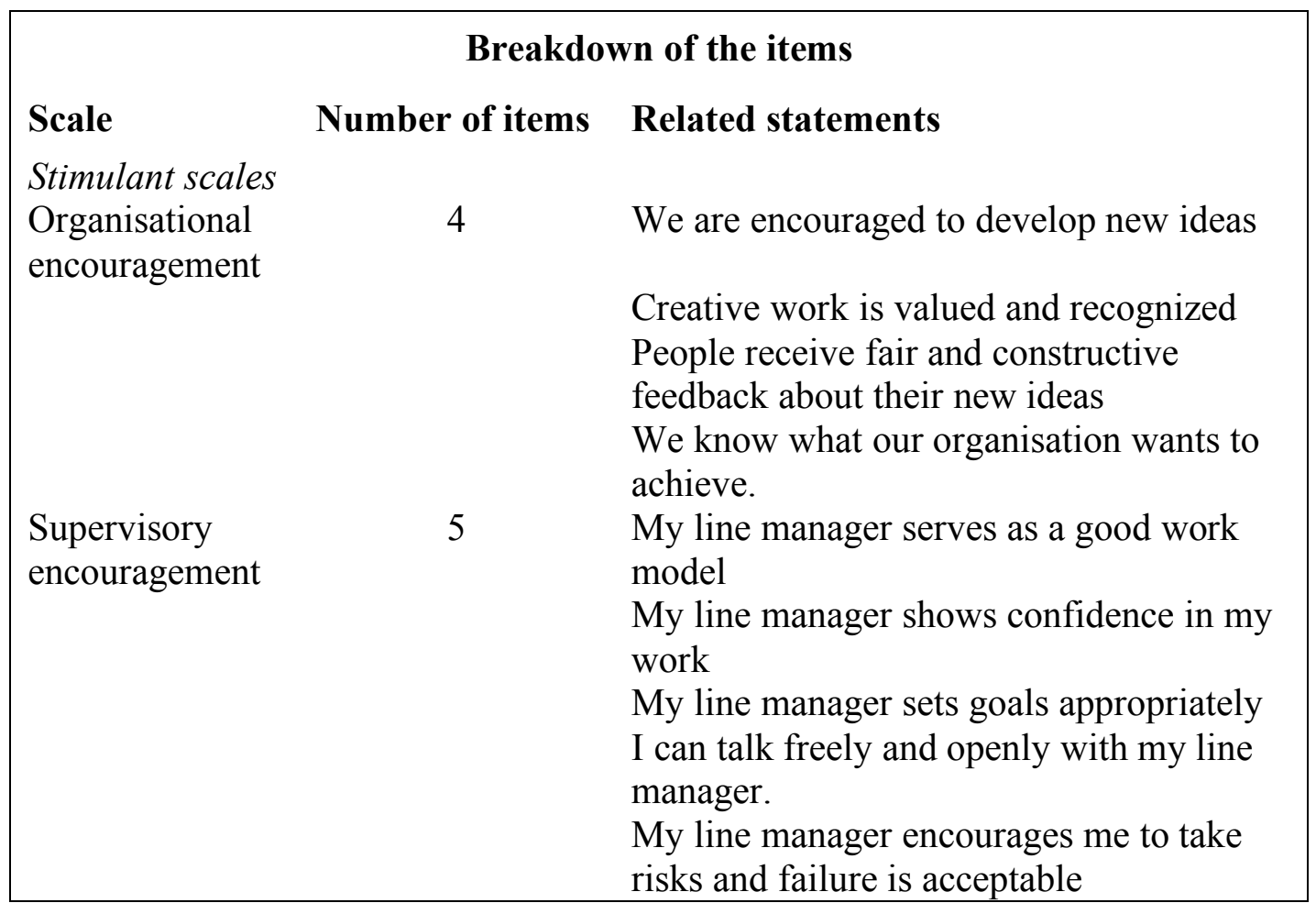




\begin{tabular}{|c|c|c|}
\hline \multicolumn{3}{|c|}{ Breakdown of the items } \\
\hline Scale & Number of items & Related statements \\
\hline $\begin{array}{l}\text { Work group } \\
\text { support }\end{array}$ & 6 & $\begin{array}{l}\text { We get along well and treat each other } \\
\text { fairly } \\
\text { People's different backgrounds help us to } \\
\text { develop new ideas } \\
\text { We respect everyone's contributions } \\
\text { We like to pick each other's brains as it } \\
\text { offers a variety of options to resolve } \\
\text { problems } \\
\text { We have a shared commitment to make } \\
\text { our project a success } \\
\text { We constructively challenge each other's } \\
\text { ideas }\end{array}$ \\
\hline Freedom & 1 & $\begin{array}{l}\text { I have the freedom to decide how I am } \\
\text { going to carry out my own work }\end{array}$ \\
\hline $\begin{array}{l}\text { Sufficient } \\
\text { Resources }\end{array}$ & 1 & $\begin{array}{l}\text { Generally, I can get the resources I need } \\
\text { for my work }\end{array}$ \\
\hline $\begin{array}{l}\text { Challenging } \\
\text { Work } \\
\text { Obstacles scales }\end{array}$ & 1 & $\begin{array}{l}\text { My work provides me with stimulating } \\
\text { challenges }\end{array}$ \\
\hline $\begin{array}{l}\text { Organisational } \\
\text { Impediments }\end{array}$ & 3 & $\begin{array}{l}\text { There are many political problems in my } \\
\text { organisation } \\
\text { The internal competition is high and } \\
\text { people do not trust each other } \\
\text { I don't dare doing anything different for } \\
\text { fear of failing or being negatively } \\
\text { criticized }\end{array}$ \\
\hline $\begin{array}{l}\text { Workload } \\
\text { pressure }\end{array}$ & 3 & $\begin{array}{l}\text { I have too much work to do in too little } \\
\text { time } \\
\text { Deadlines have a positive impact on my } \\
\text { work } \\
\text { I feel too often distracted by colleagues, } \\
\text { emails... }\end{array}$ \\
\hline
\end{tabular}

Table 1: Distributions of the survey statements according to their categories

The 2 criterion scales (creativity and productivity) were excluded from the survey mainly for two reasons:

- The need to keep the survey as brief as possible

- The focus of the study was to identify to what extent the 5 key elements which Amabile et al. (1996) hypothesise influence organisational creativity are present in this Public Library service, and not how staff perceive the level of creativity and the level of production of creative outputs in their organisation. 


\subsubsection{Breakdown of the Staff Structure}

Data was collected breaking down the staff structure by their work location and consists of 3 locations. It was also important to check whether the full spectrum of the population was represented. The level of responsibilities using the salary grades within the library service was felt to be the most appropriate way of doing this.

\subsubsection{In-Depth Interviewing}

This survey technique consists of gathering qualitative data using both semistructured and unstructured interviews, which were conducted in person.

The main aims of using this technique were:

- To compensate the limitations of the first technique, in which the respondents can only reply to the pre-determined questions, using the set of answers offered.

- To use the KEYS environment scales as a support for interviewees to identify to what extent the given dimensions have been particularly determinant in creative projects or activities.

- To identify if there are any other internal factors not identified in the KEYS environment scales conducive to creativity.

- To gain some background knowledge about the organisation, as we cannot understand the behaviour of members of a social group other than in terms of a specific environment in which they operate (Bryman, 2001, 279).

\subsection{Data analysis}

Quantitative data and qualitative data resulting respectively from the selfcompletion questionnaire and the in-depth interviews require different approaches to analysis.

For the quantitative data, most of the variables were ordinal. Some of the analysis was univariate and some bivariate and the results are presented in various forms including frequency tables, diagrams. Likely relationships were explored and explanations offered where possible.

For the qualitative data, the results transcribed the main concepts highlighted by the interviewees, and offered some valuable additional information in which the quantitative data can be contextualized.

Finally, comparisons with similar studies using either qualitative or quantitative data were drawn. However, many of the conclusions are necessarily tentative and several of the areas explored would require further and more substantial research particularly in an information profession work environment. 


\subsection{Limitations and lessons learned}

The analysis of results has revealed a number of areas in the methodology that could have been improved, in particular in the design of the online questionnaire. Some results, especially in categories with multiple statements, have displayed excessive findings, with grade categories comprising less than three people and being difficult to validate. Dividing the structure into four broader variables would have avoided this situation. Another piece of information that would have been useful to collect is whether staff were full-time or part-time in the organisation, as this would have enabled exploration as to whether this had an impact on the staff's responses.

\section{Findings at BANES Library \& Information Service}

Even if the findings were interesting, they do not allow for generalisations as the response rate from the questionnaire was $23.27 \%$ and there were two volunteers for the interviews. The results can only be considered representative of the respondents' own views and cannot represent the perceptions of the whole staff of this organisation. The results that came out the questionnaires and the in-depth interviews show nevertheless some trends worth commenting upon and offer a starting-point for improved understanding.

Maybe the first impression that comes to mind is that the results are overall very positive and it would be legitimate to question whether the findings may suffer from a certain halo effect. When designing the online questionnaire, attention was paid to write positive as well as negative statements in order to avoid expected answers from the respondents. Another opposite concern was that the questionnaire might generate excessively negative results, particularly common in a "blame culture". The final results suggest that the surveyed population had a consistently positive perception of their work environment, and this appears to echo one of the observations from the IDeA Peer Review, which gave a very clear indication that the service had a no-blame culture: "...the peer review team strongly identified with the complete lack of any blame culture amongst staff and members. This is a sign of a healthy organisation and augurs well for the future.", This fact seems to support the positive results found for work group support, supervisory encouragement and to a certain extent organisational encouragement as well as accounting for the perceived absence of organisational impediments.

The research found, from the surveyed population, that BANES Library Service is organised in a way that allows them to develop the six dimensions enabling creativity: work group support, freedom and supervisory encouragement being the highest rated factors. Dimensions hampering creativity scored a relatively low result among the same population although workload pressures appeared to be an issue on a daily basis for $30.61 \%$ of respondents and for $30.76 \%$ as a regular problem.

\footnotetext{
${ }^{2}$ An IDeA Peer Review, designed to help the library service to assess its current achievements and its capacity to change, was carried out in April 2005 at BANES Library service.
} 


\subsection{Organisational Encouragement}

There was a strong sense from the information gathered during the in-depth interviews that organisational goals and objectives were used on a systematic basis at the start of a new project. It appeared that the lower the employees were in the hierarchy, the less aware they were of the organisation's objectives. Unfortunately, the questionnaire does not provide evidence that these employees could possibly work part-time in the service. Both interviewees stressed the importance of setting up clear boundaries in which creativity could take place and this seems to echo the views of Judge et al. (1997) who describe successful innovation as "chaos within guidelines" that allow freedom in the context of the goals. Clear communication was stressed to be an important element by both interviewees as a means to establish a climate of confidence and trust within the organisation, one interviewee recognised that senior managers were much encouraged to develop new ideas and this had a positive impact in building up their own level of confidence.

\subsection{Supervisory Encouragement}

A high level of confidence is also perceived through the organisation as $73.05 \%$ of the respondents surveyed believed that their line manager showed confidence in their work. Communication for $65.38 \%$ of the respondents was felt to be constantly free and open with their line managers. Interviewee 2 described open communication as a "two-way process". She stressed the importance of listening to library representatives' suggestions and of giving evidence that they are put into place the following year. This can reinforce the message for staff that their ideas are valued and recognised and this mutual openness to ideas can be seen as operating through the same mechanisms that are associated with fair, supportive evaluation.

Reward methods were briefly overviewed by one interviewee and were related to good work, to reward individuals, or used as an incentive to increase team performance; however she was not certain of their effectiveness and favoured methods that reward teams rather than individuals. Reward methods as a means to motivate or inspire staff to become more creative have been reviewed in the literature with warnings: Tushman and O'Reilly (1997) stressed the importance for managers to be sensitive to which methods of rewards and recognition will inspire staff (at an individual as well as a team level) in their specific organisation to develop their creative skills. Amabile et al. (1986) pointed out that creativity can be enhanced by staff expecting a reward as a supplementary bonus: a confirmation of one's competence and a means to do more interesting work in the future. On the other hand, rewards that are perceived as a means to an end can undermine creativity.

\subsection{Work group support}

Work group support appeared to generate the highest scores as most of the respondents $(76.92 \%)$ believed that the staff in the organisation always or almost always get on well and treat each other fairly. Possibly a disadvantage of developing a highly friendly atmosphere within an organisation is that staff may feel pressured to constructively challenge other colleagues in looking for new and 
improved ways of working. The results in this area were relatively low $(26.92 \%)$ meaning that staff always or almost always constructively challenge each other's ideas compared with other results in this category. This view is also acknowledged in one of the interviews: "...you are paid to manage, not to be nice to people and we do that too much..."

People's different backgrounds are perceived more as assets to develop new ideas than as barriers for homogeneity or for a shared commitment to make a project a success. Both interviewees stressed that the work involved in a library service has changed over the years and it was more important to have the required skills to do a job regardless of one's background than to have simply a qualification in librarianship. Having a positive work environment, in which serious conflicts among staff are uncommon, may also lead senior staff to feel confident enough in recruiting staff from diverse backgrounds.

\subsection{Freedom, Sufficient Resources and Challenging Work}

For $80.76 \%$ of the respondents, there was a strong feeling that they were given some autonomy to decide how they carry out their own work. It was stressed in the interviews that this freedom can only exist within boundaries. A fair number of respondents considered their job offered them stimulating challenges although this was felt more strongly by the senior staff.

One of the challenges, highlighted by one interviewee was the lack of resources or their difficult position at facing a decreasing budget. Ironically, this area has led staff dealing with finances to develop their creativity in order to make the best use of the financial resources. Nevertheless, sufficient resources could become a serious problem for an organisation if one only concentrates on dealing with the existing resources without looking at the long term either to generate more income or to attract more funding in order to make the service sustainable. It could also be a source of distraction for the staff, who could focus their work on reducing the resources to the minimum instead of concentrating their efforts on creating services that add value for the library users.

\subsection{Workload Pressures}

Workload pressures were perceived as significant by $30.61 \%$ of the respondents, who believed that they were working constantly under pressure and $30.76 \%$ felt pressured on a regular basis. The workload pressures were perceived across the organisation, however to a lesser extent by library assistants. It was stressed by one interviewee that time pressure affects people differently and deadlines can be perceived as having a negative impact on someone's work but can be equally perceived as a useful tool for someone else.

Smaller structures were said by one of the interviewees to facilitate quick decision processes as they involved a limited number of people. But they may also lead staff to have more roles to play in the organisation and responsibilities to deal with and as a consequence, prevent staff from having time to generate new ideas. Filipczak (1997) noted that organisations where creativity and innovation were encouraged allowed $15 \%$ of their personnel's time for generating new ideas and working on their favourite projects. However, too much emphasis on productivity 
and downsizing means staff to have to work harder and has a negative impact on creativity.

\subsection{Organisational Impediments}

Organisational impediments did not seem to be significant in the results from either the quantitative or qualitative data collected at BANES Library Services. A general impression gathered from the interviews was that staff with more conventional skills or qualifications might consider that their role within the service was less valued and as a consequence might feel less ready to share their expertise in creating reader development activities or services for the benefit of the library users.

\subsection{Additional factors}

Some additional factors that were not explicitly developed in the questionnaire were provided during the in-depth interviews. Three main areas were described as promoting creativity within the library service: small structure, training and the recruitment of creative people. Small structures were highlighted by both interviewees as having a positive impact on creativity and the implementation of new ideas. One interviewee stressed that smaller structures enable staff to make decisions more quickly than in bigger structures, involving fewer people to find common ground. This view is also shared by Tushman and O'Reilly (1997) who claim that cultural norms that lead to quick decision making (such as "speed is important" and "the work rate is fast") should promote the implementation of new ideas. The same interviewee also believed that another advantage of having a small structure when managing change was the relative ease in identifying blockages or individuals resisting change, which would help to find adequate solutions during the change process. One can also deduce that smaller structures require less rigid and formal procedures with fewer levels in the hierarchy to enable a genuine flow of ideas, however one possible disadvantage for some members of staff working in small structures would be to have broadly defined job responsibilities and this may lead them to suffer more severely from workload pressures.

Training was also mentioned by both interviewees as enabling the staff to have the right tools to implement change, more precisely for developing new strategies and working differently. Interviewee 2 felt strongly about the benefit she gained from her coaching training as she was now confident to challenge and encourage staff in finding solutions to problems they raised. Training was considered on the whole as raising the staff's level of confidence in implementing change within the organisation.

Another clear indication that BANES is promoting a culture that nurtures creativity is the recruitment of creative people. One of the interviewees was responsible for recruiting new staff and stated that she paid particular attention to ensuring that the keywords "creative", "passionate" and "enthusiastic" were part of the job description or the job specification. As the values and beliefs of management are reflected in the type of people that are appointed, it has been demonstrated that the recruitment and the appointment of employees play an 
important part in promoting and stimulating a desired orientation, such as creativity in an organisation (Gardenswartz and Rowe, 1998).

\section{Comparisons of the current findings with other similar studies}

A number of studies have focused on the impact of the work environment on creativity. A lot of research has been carried out in the private sector in the United States, which includes the work by Amabile et al. However, Ensor et al. (2001, 2006) have based their research on the UK advertising agencies and the aim of their studies was to identify whether the work environment of advertising agencies in the UK presented the key factors (both positive and negative) of the conceptual categories which Amabile et al. hypothesised to influence organisational creativity. Two studies were carried out:

- one that involved in-depth interviewing in six London-based advertising agencies (Ensor et al., 2001) and

- another (Ensor et al., 2006) that gathered quantitative data using the KEYS instrument designed by Amabile et al. in two London-based advertising agencies. A stratified sampling approach was adopted and the response rate was $63 \%$ of the 203 individuals surveyed.

The findings from the first study revealed that UK advertising agencies were organised in a way that enables them to strongly develop the work dimensions that enhance a creative work environment. The factors that usually hamper creativity in a work environment were perceived by the interviewees from the UK advertising industry as largely insignificant. One similarity with the current study is that the in-depth interviews were also undertaken by representatives of the senior management, whose views may differ from those at different levels within the organisation.

Ensor et al.'s (2001) findings also identified additional factors:

- team building;

- recruitment;

- mentoring;

- age profile.

Most of the advertising work is based on project and teamwork and it was felt that the capacity to constantly build and dismantle teams was essential in order to deliver creative products against tight deadlines. Meeting deadlines was not perceived as necessarily a negative factor, although it was recognised that the accumulation of continual deadlines can potentially lead to creative burnout.

In contrast with library staff, most of the workforce employed in the advertising industry are young as they are under 40 . One may be inclined to believe that young staff may be more attracted to work in a fast-paced environment. Training was also identified as an important factor to foster creativity, however approaches in training staff were significantly different from BANES Library service. The library service provided formal courses while the advertising agencies believed that mentoring was a critical factor in supporting creativity. This difference could 
be related to the relatively young age of the staff employed in UK advertising agencies, compared to a library service environment.

The findings from the advertising agencies and BANES Library service stressed the importance of developing a "no blame" culture so that individuals have the freedom not to confront to established patterns of thinking.

The second study carried out by Ensor et al. (2006) gives more precise results on organisational creativity in UK advertising agencies. The main advantages of this study were that:

- the original KEYS instrument was used and therefore valid comparisons in results could to be generated against the KEYS database, which offers a norm;

- the KEYS instrument enables respondents to answer open-ended questions;

- the results were collected recently and were based on the same culture, whose staff share a similar Weltanschauung, "worldview" and assumptions shared by people who live in the same country at the same period of time.

Their main findings demonstrated that there were no significant differences from the KEYS database on the dimensions concerning supervisory encouragement, freedom and creativity.

However, the advertising agencies' results were higher on the work group support, sufficient resources, productivity, lack of organisational impediments and low work pressures scales. Nevertheless, on the challenging work scale, the results were lower than those on the KEYS database. Overall the findings of Ensor et al.'s research support key aspects of Amabile et al.'s conceptual framework. However it was suggested that further refinements to the KEYS instrument are needed especially with regards to the category on pressures (challenging work and time). As stressed by one of the BANES Library Service's interviewees, time pressure on creativity can have positive and negative effects depending on the individual's intrinsic motivation. Amabile et al. (2002b) suggested that if further research supported their findings on time pressure, then the conceptual model should be modified in order to take into account the positive and negative effects that time pressure can have on various individuals.

The main similarities between the present findings and those from the UK advertising industries are that they both stressed the importance of developing a non-blame culture and generated a high score on the work group support dimension. A lack of organisational impediments was also a common factor in fostering creativity for both sectors. However, the main differences between the types of organisation seem to lie within the workload pressures and sufficient resources dimensions, where they were perceived as challenging at BANES Library Service. But this could merely be highlighting a difference between larger and smaller structures or between organisations from the private and the public sectors. 


\section{Conclusion}

The current study aimed to explore the area of creativity within a Public Library service and adapted Amabile et al.'s conceptual model to assess for the first time whether its work environment fosters creativity. Many of the conclusions are necessarily tentative. An assessment tool that would encompass strategies in involving the public in generating new ideas, occasionally described as tapping the ideas of customers or learning from Lead Users (HMM Managing for Creativity and Innovation, 2003) or Library Friends' Groups, would certainly add value to the exercise. The study did not explore specifically to what extent the use of new technologies could facilitate the generation of new ideas within a work environment and this approach would certainly generate some interesting findings.

\section{References}

Amabile, T.M. (1996) Creativity in context. New York, NY: Westview Press.

Amabile, T.M., Conti, R., Coon, H., Lazenby, J., and Herron, M. (1996)

Assessing the work environment for creativity, Academy of Management Journal, 39(5), 1154-1185.

Amabile, T.M., Hennessey, B.N. and Grossman, B.S. (1986) Social influences on creativity: the effect on contracted-for reward, Journal of Personality and Social Psychology, 50(1), 14-23.

Amabile, T.M., Hadley, C.N. and Kramer, S.J. (2002a) Creativity under the gun, special issue on the innovative enterprise: turning ideas into profits, Harvard Business Review, 80(8), 52-61.

Amabile, T.M., Mueller, J.S., Simpson, W.B., Hadley, C.N., Kramer, S.J. and Fleming, L. (2002b) Time pressure and creativity in organizations: a longitudinal field study, Working paper No. 02-073. Cambridge, MA: Harvard Business School, 1-23.

Anderson, N. R. and West M.A. (1998) Measuring climate for work group innovation: development and validation of the climate inventory, Journal of Organizational Behavior, 19(3), 235-258.

Birkinshaw, J. and Gibson, C. (2005) The ambidextrous organisation. London: Advanced Institute of Management Research.

Borghini, S. (2005) Organizational creativity: breaking equilibrium and order to innovate, Journal of Knowledge Management, 9(4), 19-33.

Bryman, A. (2001) Social research methods. Oxford: Oxford University Press.

Chan, D. (1998) Functional relations among constructs in the same content domain at different level of analysis: a typology of compositions models, Journal of Applied Psychology, Vol. 83(2), 234-246. 
Deiss, K. J. (2004) Innovation and strategy: risk and choice in shaping usercentered libraries, Library Trends, 53(1), 17-32.

Drazin, R., Glynn, M.A. and Kazanjian, R.K. (1999) Multilevel theorizing about creativity in organizations: a sense-making perspective, Academy of Management Review, 24(2), 286-307.

Drucker, P.F. (1985) Innovation and entrepreneurship. London: William Heinemann Limited.

Ensor, J., Cottam, A. and Band, C. (2001) Fostering knowledge management through the creative work environment: a portal model from the advertising industry, Journal of Information Science, 27(3), 147-155.

Ensor, J., Pirrie, A. and Band, C. (2006) Creativity work environment: do UK advertising agencies have one? European Journal of Innovation Management, 9(3), 258-268.

Filipczak, B. (1997) It takes all kinds: creativity in the workforce, Training, 34(5), $32-40$.

Gardenswartz, L. and Rowe, A. (1998) Why diversity matters, HR Focus, 75(7), 51-53.

Harvard Business School (2003) Managing creativity and innovation. Boston, MA: Harvard Business School Press.

Heye, D. (2006) Creativity and innovation: two key characteristics of the successful $21^{\text {st }}$ century information professional, Business Information Review, 23(4), 252-256.

House, R., Rousseau, D.M. and Thomas-Hunt, M. (1995) The meso paradigm: a framework for the integration of micro and macro organizational behaviour, Research in Organizational Behaviour, 17, 71-114.

HR Focus (2007) Creativity and innovation: must-haves for global success, 84(3), 8.

Judge, W.Q., Fryxell, G.E. and Dooley, R.S. (1997) The new task of R\&D management: creating goal-directed communities for innovation, California Management Review, 39(3), 72-85.

Light, P.C. (1998) Sustaining innovation: creating nonprofit and government organizations that innovate naturally. San Francisco: Jossey-Bass.

Marshall Egan, T. (2005) Factors influencing individual creativity in the workplace: an examination of quantitative empirical research, Advances in Developing Human Resources, 7(2), 160-181.

Mathisen G. E. and Einarsen, S. (2004) A review of instruments assessing creative and innovative environments within organizations, Creative Research Journal, 16(1), 119-140.

Mayer, R.E. (1999) Fifty years of creativity research. In: Sternberg, R.J. (ed.) Handbook of Creativity. New York, NY: Cambridge University Press. 449-460. 
Rousseau, D.M. (1985) Issues of level in organizational research: multi-level and cross-level perspectives, Research in Organizational Behaviour, 7, 1-37.

Tushman, M.L. and O'Reilly, C.A. (1997) Winning through innovation: A Practical Guide to leading Organizational Change and renewal. Boston: Harvard Business School Press.

Walton, G. (2008) Theory, research, and practice in library management 4: creativity, Library Management, 29(1/2), 125-131.

West, M.A. (2001) State-of-the-art: creativity and innovation at work, The Psychologist, 13(9), 460-464.

West, M.A. and Farr, J.L. (1990) Innovation at work. In: West, M.A. and Farr, J.L. (eds.) Innovation and creativity at work: Psychological and organizational strategies. Chichester: Wiley. 3-13.

William, W.M. and Yang, L.T. (1999) Organizational creativity. In: R.J. Sternberg (ed.) Handbook of creativity. New York, NY: Cambridge University Press. 373-391.

Woodman, R.W., Sawyer, J.E. and Griffin, R.W. (1993) Toward a theory of organizational creativity, Academy of Management Review, 18(2), 293-321

\section{Acknowledgement}

I would like to thank BANES Information and Library Service and June Bassington who kindly agreed to carry out the investigation for this study, as well as Devon \& Cornwall Career Development Group for their participation in the pilot and their valuable feedback, particularly Val Bearne, and Martin Kidds for his constant professional support. 